Research Article

\title{
Research on Evaluation of Green Smart Building Based on Improved AHP-FCE Method
}

\author{
Song Xu iD and Yao Sun \\ School of Economics and Management, Anhui Jianzhu University, Hefei, Anhui, China \\ Correspondence should be addressed to Song Xu; songxuxs@gmail.com
}

Received 31 August 2021; Revised 21 October 2021; Accepted 26 October 2021; Published 26 November 2021

Academic Editor: Ahmed Mostafa Khalil

Copyright (C) 2021 Song Xu and Yao Sun. This is an open access article distributed under the Creative Commons Attribution License, which permits unrestricted use, distribution, and reproduction in any medium, provided the original work is properly cited.

With the accelerated pace of urbanization, green buildings and green smart buildings gradually come into people's vision and are highly valued by all sectors of society on the premise of meeting sustainable development strategy. Firstly, this paper selects 7 firstlevel index factors and 20 second-level index factors to establish the green smart building evaluation system. Secondly, this paper uses the analytic hierarchy process-fuzzy comprehensive evaluation (AHP-FCE) method to determine the weight of each secondary index. Finally, the feasibility of the evaluation system is verified by case analysis, and some suggestions on green smart building are put forward.

\section{Introduction}

A large number of buildings will be built in the construction of new urbanization. However, buildings are one of the largest energy consumers in the world. As people pay more and more attention to issues such as energy, environment, and sustainable development, the development of green smart architecture has become a new direction that conforms to the new urbanization construction. In the "Guiding Opinions on Accelerating the Establishment and Improvement of a Green Low-Carbon Circular Development Economic System" issued by China's State Council in February 2021, it is emphasized that green planning, green design, and green construction should be carried out in an all-round way; high-quality development and high-level protection should be promoted so as to ensure the realization of the goals of carbon peak and carbon neutrality [1]. In today's fast-developing construction industry, to achieve the goals of building energy conservation, environmental protection, and greenness and to provide humans with a safe, comfortable, and healthy production and living environment, the construction industry needs to shift from rapid development to high-quality development. Green smart building is a new-generation building incorporating BIM,
GIS, Internet of Things, cloud computing, and other technologies. It saves resources and improves energy utilization while reducing environmental pollution and resource waste and has a great effect on alleviating the current energy shortage in my country. At present, there are relatively mature evaluation standards for the evaluation of green buildings, but there are few studies on the comprehensive evaluation of green smart buildings. Combining the smart building evaluation index factors, this paper tries to build a simple and clear green smart building evaluation system based on the green building evaluation system so as to enrich the new green building evaluation standards and promote the evaluation and development of green smart buildings.

\section{Research Status}

Arkin and Paciuk pointed out that intelligent buildings are increasingly using intelligent devices, materials, and sensors. Intelligent buildings should provide environments and means for the best use of buildings. They studied some contemporary intelligent buildings based on the level of system integration [2]. Green buildings are buildings related to resource efficiency, life cycle effects, and building performance; smart buildings with integrated building 
technology systems as the core are buildings related to building and operational efficiency, as well as enhanced management and occupant functions. Sinopoli has studied the commonalities between the two [3]. Runde and Fay pointed out that building automation requires a large number of smart devices, and modern building automation systems are composed of as many as thousands of components with many attributes and dependencies [4]. Robichaud and Anantatmula's research shows that by adding a team of professionals to the project, they can promote the completion of green building projects better and faster [5]. Chen and Huang suggested the establishment of an environmental health information management platform to provide residential users with a comfortable and healthy indoor environment [6]. Balta-Ozkan et al. defined an intelligent building as a residence equipped with a communication network, linking sensors, household appliances, and devices that can be remotely monitored, accessed, or controlled to provide services that respond to the needs of its residents. They studied the similarities and differences in the technical and economic driving factors and obstacles to the development of the smart home market in three European countries characterized by different policies and socioeconomic backgrounds [7]. Shaikh et al. conducted a comprehensive and important research on the most advanced intelligent control system for energy and comfort management of intelligent energy buildings [8]. Buckman et al. claimed in 2014 that intelligence can be used interchangeably with smart, and there is no obvious difference between the two [9]. Attoue et al. proposed the concept of smart buildings to use smart technology to reduce energy consumption and improve comfort and user satisfaction [10]. Research by To et al. found that building users tend to focus more on intelligent security systems, followed by intelligent and responsive fresh air supply, elevators, and escalators [11]. Ding and Fan pointed out that most green buildings certified by rating tools are mainly evaluated based on their design and construction. The life cycle of green buildings goes beyond these initial stages, and their full benefits become more apparent during the operation phase of the building [12]. Zhao et al. reviewed and analyzed 2,980 articles published from 2000 to 2016; the results show that green building research is concentrated in the fields of engineering, environmental science, ecology, and construction technology [13]. Apanaviciene et al. research and define the characteristics that smart buildings should meet in order to be compatible with the overall background of smart cities and introduce a new evaluation framework for smart buildings to integrate into smart cities [14]. Eini et al. proposed a real-time management system to control all aspects of smart buildings and proposed the system's performance specifications, design requirements, and operational constraints [15].

Long et al. [16] started from the concept of intelligent buildings and indoor ecological environment and introduced the use of passive methods such as energy-saving windows and building exterior sunshades and the use of active methods such as displacement ventilation and cold radiation ceilings to improve the indoor environment of smart buildings. After analyzing the concept and characteristics of green building and intelligent building as well as their development status at home and abroad, Yin et al. [17] put forward the harmonious and unified view of "human, building and nature" in order to achieve the purpose of saving energy and resources, harmless, pollution-free and recyclable, harmonious and sustainable development of society. Through a large number of investigations, combined with engineering construction practices, Duan [18] integrated a variety of green building evaluation systems to develop a green construction evaluation standard for construction projects. Wang and Zhou [19] studied in depth the green building evaluation system proposed by the American LEED company and the "Green Building Evaluation Standards" issued by China and combined the two standards for comparative analysis, then constructed a simple evaluation system using AHP method. Liu and Peng [20] based on the in-depth understanding of green building and real estate development, combined green building and real estate to build a green real estate development evaluation index system, adopted AHP-FCE method to establish a green real estate evaluation model, and combined with index weights put forward policy recommendations for realizing green real estate development. Xiong et al. [21] comparatively analyzed domestic and foreign green building evaluation systems, and on this basis, they built a green intelligent building evaluation system based on the 2014 version of green building evaluation standards, established a five-level evaluation standard, and determined the weights of evaluation indicators and a comprehensive evaluation model. Wang et al. $[22,23]$ analyzed and studied the influence of EBI, FCS, and AIOT technologies on the building automation system of modern green intelligent buildings. The application of these technologies further enhanced and improved the control level, use functions, and service efficiency of green intelligent buildings. These technologies lay the foundation for the real realization of the "green" and "intelligence" of buildings and create conditions for the further transformation of intelligent buildings into super-intelligent buildings and smart buildings.

Based on academic research at home and abroad, scholars have continuously studied green buildings and intelligent buildings. The evaluation objects focused on green intelligent buildings mainly include "four savings and one environmental protection," intelligent equipment, technology, environment, materials, and management. These evaluation systems have laid the foundation for the development of green smart buildings. Under the policy background of green economy and sustainable development, we have established a green smart building evaluation system, including safety and durability, health and comfort, convenience of life, resource conservation, environmental livability, smart, innovation and characteristic indicators 
and then used the analytic hierarchy process-fuzzy comprehensive evaluation (AHP-FCE) method to determine the weight of each secondary indicator and established a fivelevel evaluation standard.

\section{Modeling Steps of Improved Analytic Hierarchy Process-Fuzzy Comprehensive Evaluation (AHP-FCE) Method}

3.1. Establish a Set of Evaluation Indicators. We need to build a judging evaluation index system for the goal. Generally speaking, the fuzzy comprehensive discriminant model includes three levels of indicators, namely, the target level, the criterion level, and the plan level factor set. The evaluation object $U$ is a collection of evaluation indicators, which is hierarchical. The first-level indicators can be established as $\left(U_{i}\right), i=1,2,3, \cdots, n$, so the index system is

$$
U=\left(U_{1}, U_{2}, \cdots, U_{n}\right) .
$$

The secondary indicators can be established as $\left(U_{i j}\right)$, so

$$
U_{i}=\left(U_{i 1}, U_{i 2}, \cdots, U_{i N_{i}}\right), \quad i=1,2, \cdots, n,
$$

$N_{i}$ is the number of secondary indicators included in $U_{i}$.

\subsection{Establish Evaluation Grade.}

$$
V=\left(V_{1}, V_{2}, \cdots, V_{K}\right),
$$

where $V_{j}(j=1,2, \cdots, K)$ is the classification of different grades.

\subsection{Construct Fuzzy Relation Matrix}

\subsubsection{Construct Judgment Matrix $U *$.}

$$
U *=\left[\begin{array}{cccc}
u_{11} & u_{12} & \cdots & u_{1 n} \\
u_{21} & u_{22} & \cdots & u_{2 n} \\
\vdots & \vdots & \ddots & \vdots \\
u_{n 1} & u_{n 2} & \cdots & u_{n n}
\end{array}\right],
$$

where $u_{i j}=\left\{0\right.$, the $i$ factor $U_{i}$ is not as important as the $j$ factor $U_{j}, 1$, the $i$ factor $U_{i}$ and the $j$ factor $U_{j}$ are equally important, 2 , the $i$ factor $U_{i}$ is more important then the $j$ factor $U_{j}$, .

For the fuzzy relation matrix, also known as the membership matrix, it is necessary to establish not only the comment set, but also the membership set of grade factors. In this way, after quantitative analysis, the specific position of each factor that may affect the evaluation object in the grade can be determined so as to form the fuzzy relation matrix $P$ :

$$
\begin{array}{r}
P_{U_{k}}(i, j)=p_{i j}^{k}, \quad k=1,2, \cdots, n, i=1,2, \cdots, N_{k}, \\
j=1,2, \cdots, K,
\end{array}
$$

where $p_{i j}^{k}=v_{i j k} / M$, where $v_{i j k}$ is the number of experts who believe that $U_{k i}$ is affiliated to $V_{j}$ among all experts. $M$ is the total number of experts.

3.4. Calculate Weight Using Improved AHP Method. AHP analytic hierarchy process is a multiobjective decision analysis method that combines qualitative and quantitative analysis methods. The improved analytic hierarchy process in this article is based on the traditional analytic hierarchy process, draws lessons from the methods in Ba's academic achievements [24], and makes changes in the strategy of constructing the judgment matrix. The previous nine-scale method is replaced by a more concise three-scale method, which makes it easier for experts to understand. Judging and scoring is more intuitive. The improved AHP method improves the accuracy of judgment, and the consistency check step can be omitted after using the optimal transfer matrix, which reduces the computational workload $[25,26]$.

Then, we solve the element $h_{i j}$ in the judgment matrix $H$ :

$$
h_{i j}=\left\{\begin{array}{cc}
\frac{\left(r_{i}-r_{j}\right)\left(k_{m}-1\right)}{r_{\max }-r_{\min }}+1, & r_{i} \geq r_{j}, \\
{\left[\frac{\left(r_{j}-r_{i}\right)\left(k_{m}-1\right)}{r_{\max }-r_{\min }}+1\right]^{-1}} & r_{i}<r_{j},
\end{array}\right\},
$$

where $r_{i}=\sum_{j=1}^{n} u_{i j}, r_{\max }=\max \left(r_{i}\right), k_{m}=r_{\max } / r_{\min }$.

Let $E=\left[e_{i j}\right]_{n \times n}$, where

$$
\begin{aligned}
& q_{i j}=\log h_{i j}, \\
& d_{i j}=\frac{1}{n} \sum_{k=1}^{n}\left(q_{i k}-q_{j k}\right),
\end{aligned}
$$

$$
e_{i j}=10^{d_{i j}}
$$

Calculate $M_{i}$, the product of each row element of matrix $E$ constructed above, then calculate its $n$th root. The result is as follows:

$$
W_{i}=\sqrt[n]{M_{i}}=\sqrt[n]{\Pi e_{i j}}
$$

Normalize the vector $W$ to get $W_{i}^{\prime}: W_{i}^{\prime}=\left(w_{i} / \sum_{i=1}^{n} w_{i}\right)$; finally, we can get the weight vector $W$ of $n$ elements:

$$
W=\left(W_{1}, W_{2}, \cdots, W_{n}\right) .
$$

\section{Green Smart Building Evaluation Index System Based on Improved AHP-FCE Method}

To build a more systematic and comprehensive evaluation system for green smart building projects, it is necessary to select the first and second indicators and the corresponding scoring rules, and the indicators should be relatively independent so as to avoid the appearance of redundant and miscellaneous indicators. At the same time, in order to facilitate the understanding of calculations and applications, 
the construction of the index system should also be simple and easy to implement. Following the principles of systemicity, dynamics, and relative independence, combined with China's latest "Green Building Evaluation Standard" (GB/T50378-2019) and the group standard "Smart Building Evaluation Standard" issued by China Building Energy Conservation Association in 2021, we have built an evaluation index system for green smart buildings in Table 1.

\section{Empirical Analysis}

Xiang'an Zhengrong Mansion is located at the intersection of Shamei Road and Xiang'an South Road. It was built by XM Zhengpeng Real Estate Co., Ltd. The total construction area of the project is $114,307.13$ square meters, covering an area of $27,595.52$ square meters, the greening rate is $30 \%$, and the plot ratio is 2.8. The planned properties include commercial streets, landscape gardens, and basketball courts. The project is surrounded by Xiangshan Park and Shamei Park. The environment is beautiful, and it is close to the subway entrance and exit, making travel very convenient.

5.1. Building Evaluation System Based on Improved AHP-FCE Model. Next, we use the improved AHP-FCE method to comprehensively evaluate the green wisdom project level of Xiang'an Zhengrong Mansion in combination with the 7 primary index factors and 20 secondary index factors listed in Table 1.

5.2. Construction ofJudgment Matrix and Single-Layer Weight Calculation. According to the green smart building evaluation index system established in Table 1, the hierarchical structure is constructed by combining the interrelationships between the indicators. Experts from the green smart building and real estate industries are invited to compare and score each factor. A judgment matrix is constructed, and the corresponding weights are calculated. The results are as follows:

$$
U *=\left[\begin{array}{lllllll}
1 & 2 & 2 & 0 & 2 & 0 & 2 \\
0 & 1 & 2 & 0 & 1 & 0 & 2 \\
0 & 0 & 1 & 0 & 0 & 0 & 2 \\
2 & 2 & 2 & 1 & 2 & 1 & 2 \\
0 & 1 & 2 & 0 & 1 & 0 & 2 \\
2 & 2 & 2 & 1 & 2 & 1 & 2 \\
0 & 0 & 0 & 0 & 0 & 0 & 1
\end{array}\right] .
$$

Calculate according to the steps of the improved fuzzy comprehensive evaluation method, and get the weights of each criterion layer (first-level indicators):

$$
\begin{aligned}
W_{U}= & \left(W_{U_{1}}, W_{U_{2}}, W_{U_{3}}, W_{U_{4}}, W_{U_{5}}, W_{U_{6}}, W_{U_{7}}\right), \\
= & (0.1481,0.0607,0.0253,0.3451, \\
& 0.0607,0.3451,0.0151) .
\end{aligned}
$$

Using the same method and principle, construct the judgment matrix of the index layer (secondary indicators) against the criterion layer:

Safety and durability indicators $U_{1}=\left(U_{11}, U_{12}\right)$, $U_{1} *=\left[\begin{array}{ll}1 & 2 \\ 0 & 1\end{array}\right]$.

Health and comfort indicators $U_{2}=\left(U_{21}, U_{22}, U_{23}, U_{24}\right)$, $U_{2} *=\left[\begin{array}{llll}1 & 2 & 0 & 0 \\ 0 & 1 & 0 & 0 \\ 2 & 2 & 1 & 0 \\ 2 & 2 & 2 & 1\end{array}\right]$.

Convenience of life indicators $U_{3}=\left(U_{31}, U_{32}, U_{33}\right), U_{3} *=\left[\begin{array}{lll}1 & 0 & 0 \\ 2 & 1 & 2 \\ 2 & 0 & 1\end{array}\right]$.

Save resources indicators $U_{4}=\left(U_{41}, U_{42}, U_{43}, U_{44}\right)$, $U_{4} *=\left[\begin{array}{llll}1 & 0 & 0 & 0 \\ 2 & 1 & 2 & 2 \\ 2 & 0 & 1 & 2 \\ 2 & 0 & 0 & 1\end{array}\right]$.

Livable environment indicators $U_{5}=\left(U_{51}, U_{52}\right)$, $U_{5} *=\left[\begin{array}{ll}1 & 2 \\ 0 & 1\end{array}\right]$.

Smart $U_{6} *=\left[\begin{array}{lll}1 & 0 & 0 \\ 2 & 1 & 0 \\ 2 & 2 & 1\end{array}\right]$.

indicators

$U_{6}=\left(U_{61}, U_{62}, U_{63}\right)$,

Innovation and $U_{7}=\left(U_{71}, U_{72}\right), U_{7} *=\left[\begin{array}{ll}1 & 1 \\ 1 & 1\end{array}\right]$.

Calculate according to the improved method, and get the weight of each indicators layer (secondary indicators):

Safety and durability index weight $W_{U_{1}}=(0.7500,0.2500)$.

Health and comfort index weight $W_{U_{2}}=(0.1178,0.0550,0.2634,0.5638)$.

Convenience of life index weight $W_{U_{3}}=(0.1047,0.6370,0.2583)$.

Save resources index weight

$W_{U_{4}}=(0.0550,0.5638,0.2634,0.1178)$.

Livable environment index weight

$W_{U_{5}}=(0.7500,0.2500)$.

Smart index weight $W_{U_{6}}=(0.1047,0.2583,0.6370)$.

Innovation and characteristics index weight $W_{U_{7}}=(0.5000,0.5000)$.

5.3. Calculation of the Composite Weight of Each Layer Element to the Target Layer. Through the above calculation and evaluation results, the weight of each indicator for comprehensive evaluation of green smart building project is obtained, as shown in Table 2.

The weight distribution of indicators in Table 1 is shown in Figures 1 and 2. The main indicators that affect the evaluation of green smart buildings are save resources $\left(U_{4}\right.$, 
TABLE 1: Green smart building evaluation system.

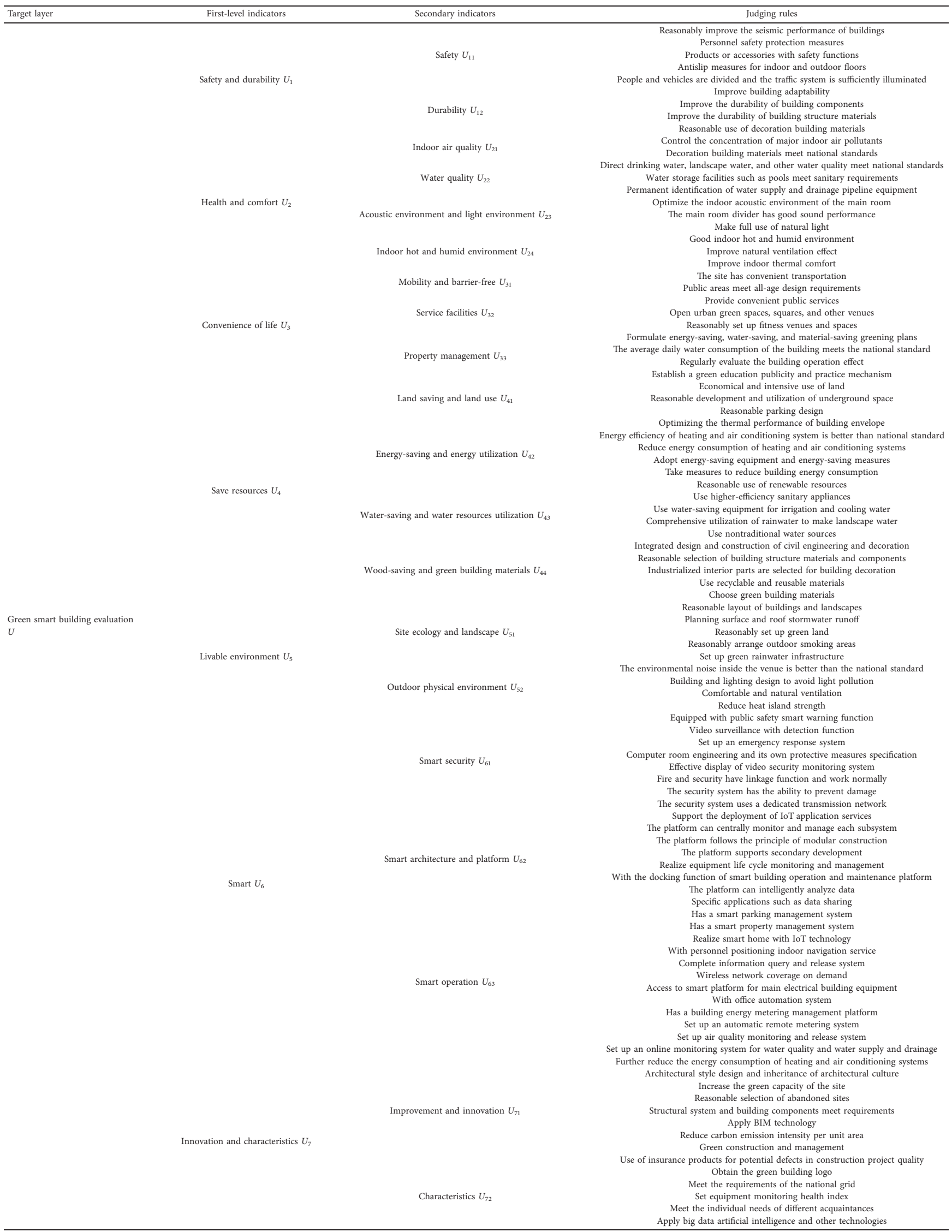

Remarks: Innovation and characteristics are the corresponding improvement of U1-U6 index factors. 
TABLE 2: Weights of comprehensive evaluation indicators of green smart building project.

\begin{tabular}{|c|c|c|c|c|c|}
\hline $\begin{array}{l}\text { Target layer } \\
U\end{array}$ & $\begin{array}{l}\text { First-level indicators } \\
\qquad U_{i} \\
\end{array}$ & $\begin{array}{c}\text { First-level } \\
\text { weight } \\
W_{i} \\
\end{array}$ & $\begin{array}{l}\text { Secondary indicators } \\
\qquad U_{i j} \\
\end{array}$ & $\begin{array}{c}\text { Secondary } \\
\text { weight } \\
W_{j} \\
\end{array}$ & $\begin{array}{c}\text { Weights } \\
W_{i j}=W_{i}^{*} W_{j}\end{array}$ \\
\hline \multirow{20}{*}{$\begin{array}{l}\text { Green smart building } \\
\text { evaluation system } U\end{array}$} & \multirow{4}{*}{ Safety and durability $U_{1}$} & \multirow{4}{*}{0.1481} & Safety $U_{11}$ & 0.7500 & 0.1111 \\
\hline & & & Durability $U_{12}$ & 0.2500 & 0.0370 \\
\hline & & & Indoor air quality $U_{21}$ & 0.1178 & 0.0072 \\
\hline & & & Water quality $U_{22}$ & 0.0550 & 0.0033 \\
\hline & \multirow[t]{2}{*}{ Health and comfort $U_{2}$} & \multirow[t]{2}{*}{0.0607} & $\begin{array}{c}\text { Acoustic environment and light } \\
\text { environment } U_{23}\end{array}$ & 0.2634 & 0.0160 \\
\hline & & & $\begin{array}{l}\text { Indoor hot and humid } \\
\text { environment } U_{24}\end{array}$ & 0.5638 & 0.0342 \\
\hline & \multirow{4}{*}{ Convenience of life $U_{3}$} & \multirow{4}{*}{0.0253} & Mobility and barrier-free $U_{31}$ & 0.1047 & 0.0026 \\
\hline & & & Service facilities $U_{32}$ & 0.6370 & 0.0161 \\
\hline & & & Property management $U_{33}$ & 0.2583 & 0.0065 \\
\hline & & & Land saving and land use $U_{41}$ & 0.0550 & 0.0190 \\
\hline & \multirow{3}{*}{ Save resources $U_{4}$} & \multirow{3}{*}{0.3451} & $\begin{array}{l}\text { Energy-saving and energy } \\
\text { utilization } U_{42}\end{array}$ & 0.5638 & 0.1946 \\
\hline & & & $\begin{array}{c}\text { Water-saving and water resources } \\
\text { utilization } U_{43}\end{array}$ & 0.2634 & 0.0909 \\
\hline & & & $\begin{array}{c}\text { Wood-saving and green building } \\
\text { materials } U_{44}\end{array}$ & 0.1178 & 0.0407 \\
\hline & \multirow{3}{*}{ Livable environment $U_{5}$} & \multirow{3}{*}{0.0607} & Site ecology and landscape $U_{51}$ & 0.7500 & 0.0455 \\
\hline & & & $\begin{array}{c}\text { Outdoor physical environment } \\
\qquad U_{52}\end{array}$ & 0.2500 & 0.0152 \\
\hline & & & Smart security $U_{61}$ & 0.1047 & 0.0361 \\
\hline & \multirow[t]{2}{*}{ Smart $U_{6}$} & \multirow[t]{2}{*}{0.3451} & $\begin{array}{l}\text { Smart architecture and platform } \\
\qquad U_{62}\end{array}$ & 0.2583 & 0.0891 \\
\hline & & & Smart operation $U_{63}$ & 0.6370 & 0.2198 \\
\hline & \multirow{2}{*}{$\begin{array}{l}\text { Innovation and } \\
\text { characteristics } U_{7}\end{array}$} & \multirow{2}{*}{0.0151} & Improvement and innovation $U_{71}$ & 0.5000 & 0.0076 \\
\hline & & & Characteristics $U_{72}$ & 0.5000 & 0.0076 \\
\hline
\end{tabular}

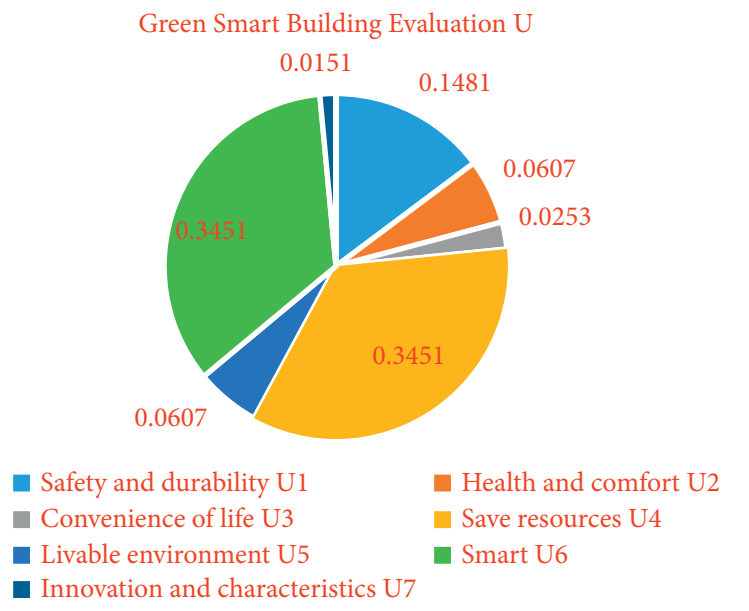

Figure 1: The weighting diagram of the criterion layer indicators.

weight is 0.3451$)$ and smart $\left(U_{6}\right.$, weight is 0.3451$)$, followed by safety and durability $\left(U_{1}\right.$, weight is 0.1481$)$. The main indicator that affects safety and durability $\left(U_{1}\right)$ is safety $\left(U_{11}\right.$, weight is 0.7500 ); the main indicator that affects health and comfort $\left(U_{2}\right)$ is indoor hot and humid environment $\left(U_{24}\right.$, weight is 0.5638$)$; the main indicator that affects convenience of life $\left(U_{3}\right)$ is service facilities $\left(U_{32}\right.$, weight is 0.6370$)$; the main indicator that affects save resources $\left(U_{4}\right)$ is energysaving and energy utilization $\left(U_{42}\right.$, weight is 0.5638$)$; the main indicator that affects livable environment $\left(U_{5}\right)$ is site ecology and landscape $\left(U_{51}\right.$, weight is 0.7500$)$; the main indicator that affects smart $\left(U_{6}\right)$ is smart operation $\left(U_{63}\right.$, weight is 0.6370 ); the main indicators that affect innovation and characteristics $\left(U_{7}\right)$ are improvement and innovation $\left(U_{71}\right.$, weight is 0.5000$)$ and characteristics $\left(U_{72}\right.$, weight is $0.5000)$.

The overall ranking of indicator weights is shown in Figure 3. Among all the impact indicators, the most important is smart operation $\left(U_{63}\right)$, followed by energy-saving and energy utilization $\left(U_{42}\right)$, followed by safety $\left(U_{11}\right)$, watersaving and water resources utilization $\left(U_{43}\right)$, and smart architecture and platform $\left(U_{62}\right)$.

5.4. Determine the Set of Evaluation Criteria. The evaluation standard set of green and smart building projects selects the five-star evaluation system in the "Smart Building Evaluation Standards," which are one-star, two-star, three-star, four-star, and five-star. Use $V$ to denote the set of evaluation criteria; then they are as follows:

$$
\begin{aligned}
V= & \left\{V_{1}, V_{2}, V_{3}, V_{4}, V_{5}\right\}, \\
= & \{\text { one }- \text { star, two }- \text { star, three }- \text { star, four } \\
& - \text { star, five }- \text { star }\}, \\
= & \{(0 \sim 20],(20 \sim 50],(50 \sim 70], \\
& (70 \sim 90],(90 \sim 100]\} .
\end{aligned}
$$




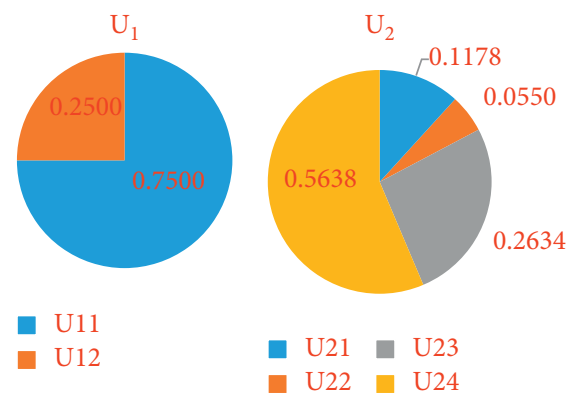

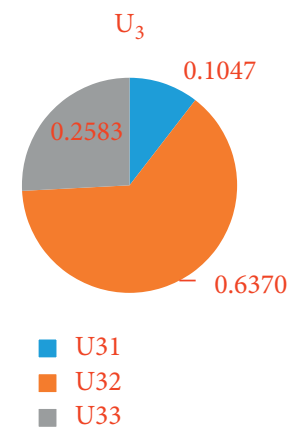

(c)

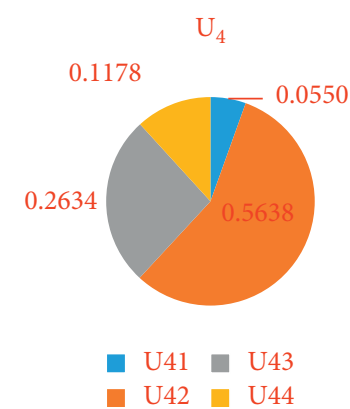

(d) (a)

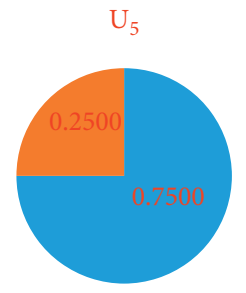

U51
U52 (b)
$\mathrm{U}_{6}$

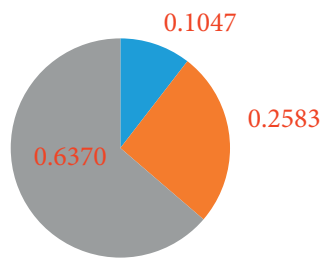

- U61

- U62

U63

(e)

(f)

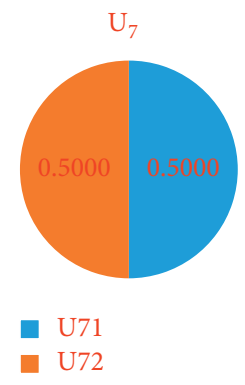

(g)

FIGURE 2: The weighting diagram of scheme layer indicators. (a) Weights of $U_{11}-U_{12}$. (b) Weights of $U_{21}-U_{24}$. (c) Weights of $U_{31}-U_{33}$. (d) Weights of $U_{41}-U_{44}$. (e) Weights of $U_{51}-U_{52}$. (f) Weights of $U_{61}-U_{63}$. (g) Weights of $U_{71}-U_{72}$.

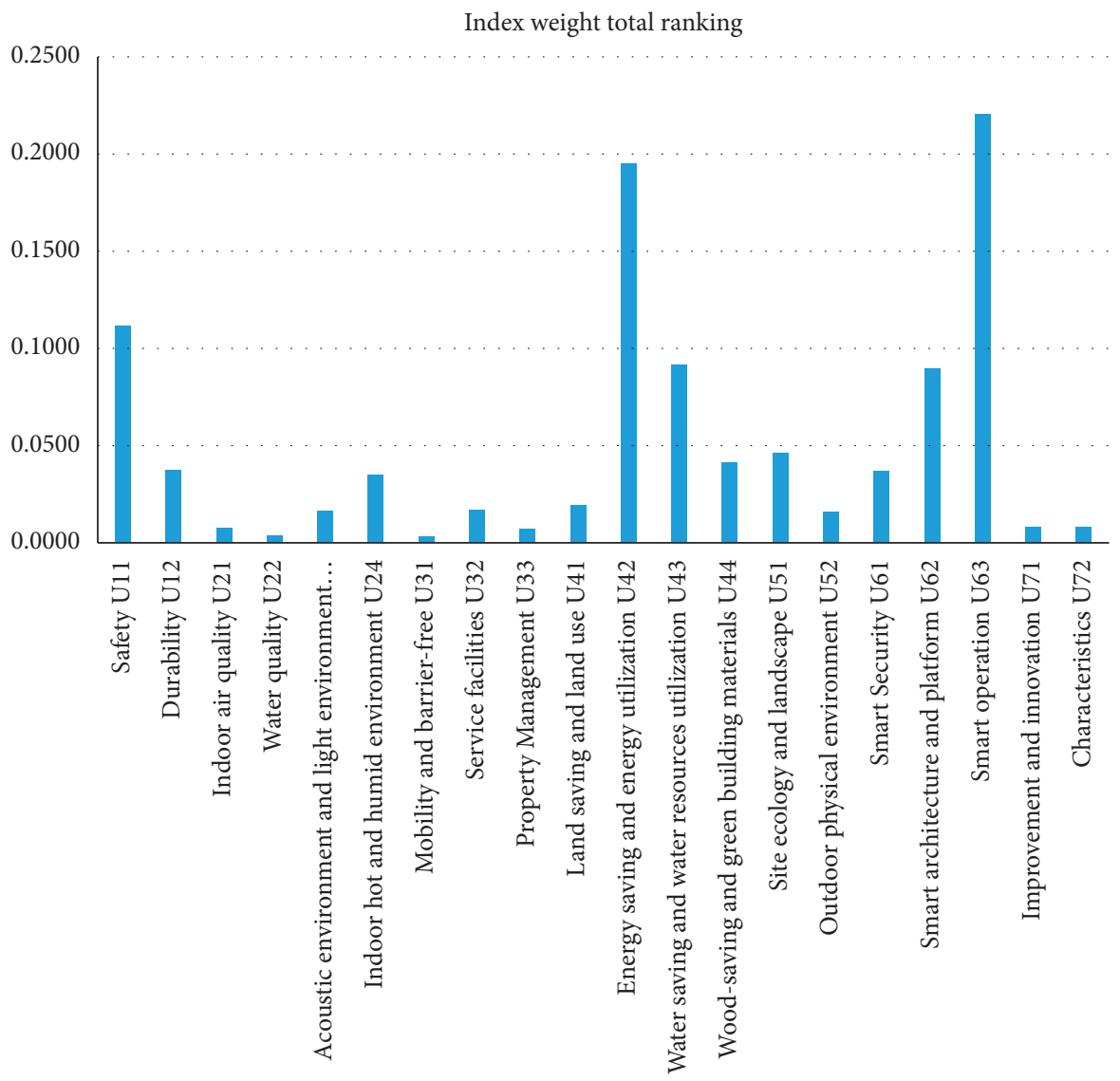

FIGURE 3: Comparison of weights of indicators. 
5.5. Fuzzy Comprehensive Evaluation of Criterion Level. According to the actual situation of the project, this paper consulted a 10-member expert group composed of experts in the construction, environmental protection, and real estate industries by collecting relevant information and using questionnaire surveys and collected the expert group's review opinions on green and smart building projects. The fuzzy evaluation matrix is as follows:

Safety and durability index matrix:

$$
P_{U_{1}}=\left[\begin{array}{ccccc}
0.2 & 0.4 & 0.2 & 0.1 & 0.1 \\
0.2 & 0.5 & 0.2 & 0.1 & 0
\end{array}\right] .
$$

Health and comfort index matrix:

$$
P_{U_{2}}=\left[\begin{array}{ccccc}
0.1 & 0.6 & 0.1 & 0.1 & 0.1 \\
0.3 & 0.4 & 0.3 & 0 & 0 \\
0.4 & 0.6 & 0 & 0 & 0 \\
0.2 & 0.5 & 0.3 & 0 & 0
\end{array}\right] .
$$

Convenience of life index matrix:

$$
P_{U_{3}}=\left[\begin{array}{lllll}
0.4 & 0.5 & 0.1 & 0 & 0 \\
0.1 & 0.5 & 0.4 & 0 & 0 \\
0.3 & 0.4 & 0.3 & 0 & 0
\end{array}\right] .
$$

Save resources index matrix:

$$
P_{U_{4}}=\left[\begin{array}{ccccc}
0.1 & 0.5 & 0.2 & 0.1 & 0.1 \\
0.1 & 0.6 & 0.2 & 0.1 & 0 \\
0.3 & 0.4 & 0.3 & 0 & 0 \\
0.2 & 0.6 & 0.2 & 0 & 0
\end{array}\right] .
$$

Livable environment index matrix:

$$
P_{U_{5}}=\left[\begin{array}{ccccc}
0.1 & 0.5 & 0.3 & 0.1 & 0 \\
0.2 & 0.6 & 0.2 & 0 & 0
\end{array}\right] .
$$

Smart index matrix:

$$
P_{U_{6}}=\left[\begin{array}{ccccc}
0.2 & 0.5 & 0.1 & 0.2 & 0 \\
0.4 & 0.4 & 0.2 & 0 & 0 \\
0.2 & 0.6 & 0.2 & 0 & 0
\end{array}\right] .
$$

Innovation and characteristics index matrix:

$$
P_{U_{7}}=\left[\begin{array}{ccccc}
0.5 & 0.5 & 0 & 0 & 0 \\
0.3 & 0.6 & 0.1 & 0 & 0
\end{array}\right] .
$$

According to the steps of the improved AHP method, the calculated weight vector $W$ of each evaluation index is established, the fuzzy evaluation matrix is established, and the comprehensive evaluation vector of the criterion layer (first-level indexes) is calculated according to the formula $Y=W \times P$.
Comprehensive evaluation vector of safety and durability index:

$$
\begin{aligned}
Y_{U_{1}} & =W_{U_{1}} \times P_{U_{1}} \\
& =(0.7500,0.2500) \times\left[\begin{array}{ccccc}
0.2 & 0.4 & 0.2 & 0.1 & 0.1 \\
0.2 & 0.5 & 0.2 & 0.1 & 0
\end{array}\right] \\
& =(0.2000,0.4250,0.2000,0.1000,0.0750) .
\end{aligned}
$$
index:

Comprehensive evaluation vector of health and comfort

$$
\begin{aligned}
Y_{U_{2}}= & W_{U_{2}} \times P_{U_{2}} \\
= & (0.1178,0.0550,0.2634,0.5638) \\
& \times\left[\begin{array}{ccccc}
0.1 & 0.6 & 0.1 & 0.1 & 0.1 \\
0.3 & 0.4 & 0.3 & 0 & 0 \\
0.4 & 0.6 & 0 & 0 & 0 \\
0.2 & 0.5 & 0.3 & 0 & 0
\end{array}\right] \\
= & (0.2464,0.5326,0.1974,0.0118,0.0118) .
\end{aligned}
$$
index:

Comprehensive evaluation vector of convenience of life

$$
\begin{aligned}
Y_{U_{3}}= & W_{U_{3}} \times P_{U_{3}} \\
= & (0.1047,0.6370,0.2583) \\
& \times\left[\begin{array}{lllll}
0.4 & 0.5 & 0.1 & 0 & 0 \\
0.1 & 0.5 & 0.4 & 0 & 0 \\
0.3 & 0.4 & 0.3 & 0 & 0
\end{array}\right] \\
= & (0.1831,0.4742,0.3428,0.0000,0.0000)
\end{aligned}
$$

Comprehensive evaluation vector of save resources index:

$$
\begin{aligned}
Y_{U_{4}} & =W_{U_{4}} \times P_{U_{4}} \\
& =(0.0550,0.5638,0.2634,0.1178)
\end{aligned}
$$

$$
\begin{aligned}
& {\left[\begin{array}{ccccc}
0.1 & 0.5 & 0.2 & 0.1 & 0.1 \\
0.1 & 0.6 & 0.2 & 0.1 & 0 \\
0.3 & 0.4 & 0.3 & 0 & 0 \\
0.2 & 0.6 & 0.2 & 0 & 0
\end{array}\right] } \\
= & (0.1645,0.5418,0.2263,0.0619,0.0055) .
\end{aligned}
$$
index:

Comprehensive evaluation vector of livable environment

$$
\begin{aligned}
Y_{U_{5}} & =W_{U_{5}} \times P_{U_{5}} \\
& =(0.7500,0.2500) \times\left[\begin{array}{ccccc}
0.1 & 0.5 & 0.3 & 0.1 & 0 \\
0.2 & 0.6 & 0.2 & 0 & 0
\end{array}\right] \\
& =(0.1250,0.5250,0.2750,0.0750,0.0000)
\end{aligned}
$$

Comprehensive evaluation vector of smart index: 


$$
\begin{aligned}
Y_{U_{6}} & =W_{U_{6}} \times P_{U_{6}} \\
& =(0.1047,0.2583,0.6370) \times\left[\begin{array}{ccccc}
0.2 & 0.5 & 0.1 & 0.2 & 0 \\
0.4 & 0.4 & 0.2 & 0 & 0 \\
0.2 & 0.6 & 0.2 & 0 & 0
\end{array}\right] \\
& =(0.2517,0.5379,0.1895,0.0209,0.0000) .
\end{aligned}
$$

Comprehensive evaluation vector of innovation and characteristics index:

$$
\begin{aligned}
Y_{U_{7}} & =W_{U_{7}} \times P_{U_{7}} \\
& =(0.5000,0.5000) \times\left[\begin{array}{ccccc}
0.5 & 0.5 & 0 & 0 & 0 \\
0.3 & 0.6 & 0.1 & 0 & 0
\end{array}\right] \\
& =(0.4000,0.5500,0.0500,0.0000,0.0000) .
\end{aligned}
$$

5.6. Fuzzy Comprehensive Evaluation of Target Layer. Using the relevant calculation rules of the fuzzy comprehensive evaluation, and according to the calculation results of the fuzzy comprehensive evaluation of the criterion layer (first-level indexes), construct the target layer fuzzy evaluation matrix of this project; then, the target layer fuzzy evaluation matrix is

$$
P_{U}=\left[\begin{array}{lllll}
0.2000 & 0.4250 & 0.2000 & 0.1000 & 0.0750 \\
0.2464 & 0.5326 & 0.1974 & 0.0118 & 0.0118 \\
0.1831 & 0.4742 & 0.3428 & 0.0000 & 0.0000 \\
0.1645 & 0.5418 & 0.2263 & 0.0619 & 0.0055 \\
0.1250 & 0.5250 & 0.2750 & 0.0750 & 0.0000 \\
0.2517 & 0.5379 & 0.1895 & 0.0209 & 0.0000 \\
0.4000 & 0.5500 & 0.0500 & 0.0000 & 0.0000
\end{array}\right] .
$$

According to formula $Y=W \times P$, the comprehensive evaluation vector of the target layer is

$$
\begin{aligned}
Y_{U}= & W_{U} \times P_{U} \\
= & (0.1481,0.0607,0.0253,0.3451,0.0607, \\
& 0.3451,0.0151) \\
& {\left[\begin{array}{lllll}
0.2000 & 0.4250 & 0.2000 & 0.1000 & 0.0750 \\
0.2464 & 0.5326 & 0.1974 & 0.0118 & 0.0118 \\
0.1831 & 0.4742 & 0.3428 & 0.0000 & 0.0000 \\
0.1645 & 0.5418 & 0.2263 & 0.0619 & 0.0055 \\
0.1250 & 0.5250 & 0.2750 & 0.0750 & 0.0000 \\
0.2517 & 0.5379 & 0.1895 & 0.0209 & 0.0000 \\
0.4000 & 0.5500 & 0.0500 & 0.0000 & 0.0000
\end{array}\right] } \\
= & \left(\begin{array}{lllll}
0.2064, & 0.5200, & 0.2112, & 0.0487, & 0.0137
\end{array}\right) .
\end{aligned}
$$

According to the principle of the maximum degree of membership, the comprehensive evaluation level of the green smart building project can be determined. The maximum comprehensive evaluation value of the green intelligent building project in this case is 0.5200 , which belongs to the two - star level of the set of evaluation criteria. Then, we use the formula $S=Y \times G^{T}$ to calculate the comprehensive evaluation value of the green smart building project and obtain the quantified comprehensive evaluation result, where the value of the quantified evaluation standard set $G$ is the median value of the corresponding value in the evaluation standard set $V$. So, the quantified comprehensive score $S$ is

$$
\begin{aligned}
S= & Y_{U} \times G^{\mathrm{T}}=(0.2064,0.5200,0.2112,0.0487,0.0137) \\
& \times(10,35,60,80,95)^{\mathrm{T}}=38.1330 .
\end{aligned}
$$

5.7. Analysis of Evaluation Results. Through the above calculations, it is shown that the project developed by XM Zhengpeng Real Estate Co., Ltd., is a two-star building. According to the quantified comprehensive evaluation calculation result, the comprehensive score of the overall evaluation of the project is corresponding to the two-star level. If you score according to the judging rules rules in Table 1, you can get consistent results. However, the judging rules' scoring method needs to determine the weight or value of the rules, which also increases the workload of the experts for scoring. The improved AHP-FCE method can reduce the corresponding workload and improve work efficiency.

\section{Conclusions and Recommendations}

From the analysis of the evaluation results, it can be seen that smart and green building sustainability have become the core of modern green buildings. The main indicators that have an impact on the development of green smart buildings include safety and durability indicators, health and comfort indicators, convenience of life indicators, save resources indicators, livable environment indicators, smart indicators, and innovation and characteristics indicators. Under the premise of these seven indicators, a fuzzy comprehensive evaluation model for green smart building projects was established, and this evaluation system was verified through corresponding cases, which further enriched the green smart building evaluation system.

In order to promote the implementation of my country's green and smart building strategy and improve the level of green economy development, the following points should be given priority: (1) Firstly, we should focus on save resources. Green smart buildings are the inevitable trend of future development. Scientific management and advanced green and clean environmental protection technologies should be used in their development so as to improve energy efficiency, reduce building energy consumption, and improve people's quality of life. Therefore, local governments should vigorously support the development of green buildings, further increase research on the development of green building products, and promulgate relevant policies for support and subsidies in order to accelerate the upgrading of the green 
and smart building industry. (2) Secondly, in terms of smart, it is necessary to make full use of the Internet of Things, 5G, big data, cloud computing, artificial intelligence, and other technologies to create an economical, safe, reliable, efficient, convenient, and green ecological living environment through automatic sensing, ubiquitous connection, timely transmission, and information integration. While strengthening the utilization of green and smart building resources, qualified enterprises should be encouraged to explore and innovate more advanced management systems and smart management. (3) In terms of safety and durability, attention should be paid to the safety and durability of buildings to avoid "fragile buildings." Starting from the full life cycle of the building, improve the seismic performance of the building and the durability of structural components, and ensure the safety of people's lives.

Green smart buildings are developing rapidly. We should constantly learn from experience and adjust the direction in the course of its development so as to explore an optimal development path. In the context of carbon peaks and carbon neutrality, leading companies in green smart buildings should adhere to the green, environmentally friendly, and healthy production concepts and strive to explore zero-carbon buildings to provide a "green model" for the development of the industry.

\section{Data Availability}

The data used to support the findings of this study are included within the article.

\section{Conflicts of Interest}

The authors declare that they have no conflicts of interest regarding the publication of this work.

\section{Acknowledgments}

This work was supported by the Key Natural Science Research Projects in Anhui Universities (KJ2019A695),Anhui Jianzhu University Research Startup Project (2019QDZ61), Key Project of Educational Commission of Anhui Province (SK2020A0261), and Anhui Province Philosophy Social Science Project for Youths (AHSKQ2020D67).

\section{References}

[1] http://www.gov.cn/zhengce/content/2021-02/22/content_ 5588274.htm, Website of the Central People's Government of the People's Republic of China.

[2] H. Arkin and M. Paciuk, "Evaluating intelligent buildings according to level of service systems integration," Automation in Construction, vol. 6, no. 5-6, pp. 471-479, 1997.

[3] J. Sinopoli, "How do smart buildings make a building green?" Energy Engineering, vol. 105, no. 6, pp. 17-22, 2008.

[4] S. Runde and A. Fay, "Software support for building automation requirements engineering-an application of semantic web technologies in automation," IEEE Transactions on Industrial Informatics, vol. 7, no. 4, pp. 723-730, 2011.
[5] L. B. Robichaud and V. S. Anantatmula, "Greening project management practices for sustainable construction," Journal of Management in Engineering, vol. 27, no. 1, pp. 48-57, 2011.

[6] S.-Y. Chen and J.-T. Huang, "A smart green building: an environmental health control design," Energies, vol. 5, no. 5, pp. 1648-1663, 2012.

[7] N. Balta-Ozkan, B. Boteler, and O. Amerighi, "European smart home market development: public views on technical and economic aspects across the United Kingdom, Germany and Italy," Energy Research \& Social Science, vol. 3, pp. 65-77, 2014.

[8] P. H. Shaikh, N. B. M. Nor, P. Nallagownden, I. Elamvazuthi, and T. Ibrahim, "A review on optimized control systems for building energy and comfort management of smart sustainable buildings," Renewable and Sustainable Energy Reviews, vol. 34, pp. 409-429, 2014.

[9] A. H. Buckman, M. Mayfield, and S. B. M. Beck, "What is a smart building?" Smart and Sustainable Built Environment, vol. 3, pp. 92-104, 2014.

[10] N. Attoue, I. Shahrour, and R. Younes, "Smart building: use of the artificial neural network approach for indoor temperature forecasting," Energies, vol. 11, no. 2, p. 395, 2018.

[11] W. To, L. Lai, K. Lam, and A. Chung, "Perceived importance of smart and sustainable building features from the users' perspective," Smart Cities, vol. 1, no. 1, pp. 163-175, 2018.

[12] Z. Ding, Z. Fan, V. W. Y. Tam et al., "Green building evaluation system implementation," Building and Environment, vol. 133, pp. 32-40, 2018.

[13] X. Zhao, J. Zuo, G. Wu, and C. Huang, "A bibliometric review of green building research 2000-2016," Architectural Science Review, vol. 62, no. 1, pp. 74-88, 2019.

[14] R. Apanaviciene, A. Vanagas, and P. A. Fokaides, "Smart building integration into a smart city (SBISC): development of a new evaluation framework," Energies, vol. 13, no. 9, p. 2190, 2020.

[15] R. Eini, L. Linkous, N. Zohrabi, and S. Abdelwahed, "Smart building management system: performance specifications and design requirements," Journal of Building Engineering, vol. 39, Article ID 102222, 2021.

[16] W. D. Long, Y. Q. Pan, and W. Bai, "The indoor ecological environment of intelligent buildings," HVAC, vol. 4, pp. 7578, 2001.

[17] B. Y. Yin, M. Lai, and F. H. Xie, "The development and application of green buildings and intelligent buildings in the world and our country," Building Technology, vol. 4, no. 10, pp. 733-735, 2006.

[18] C. W. Duan, "Establishment and research of green construction evaluation system for construction projects," Building Science, vol. 25, no. 10, pp. 35-39, 2009.

[19] Z. H. Wang and J. Zhou, "AHP-based green building evaluation system research," Construction Economy, vol. 11, pp. 79-82, 2013.

[20] G. J. Liu and S. Z. Peng, "Research on the evaluation system of green real estate development based on," AHP-FCE Resource Development and Market, vol. 33, no. 05, pp. 540-544, 2017.

[21] X. Y. Xiong, X. G. Ma, and Y. Q. Ou, "Construction and application of a comprehensive evaluation system for green intelligent buildings," Science and Technology Management Research, vol. 37, no. 03, pp. 95-99, 2017.

[22] H. Wang, Y. P. Zheng, D. H. Wu, H. T. Li, and L. S. Hu, "Integrated design and research of building automation system for green intelligent buildings based on EBI and FCS," Journal of Central China Normal University (Natural Science Edition), vol. 52, no. 5, pp. 634-641, 2018. 
[23] H. Wang, C. Han, D. D. Li, and H. T. Li, "Research on the latest development and application of AIoT technology in building automation systems for green and intelligent buildings," Journal of Central China Normal University (Natural Science Edition), vol. 55, no. 1, pp. 52-60, 2021.

[24] Z. N. Ba, Z. K. Wang, J. W. Liang, Y. X. Han, and M. S. Wang, "Corrosion risk assessment of gas pipeline network in Suzhou Industrial Park," Oil \& Gas Storage and Transportation, vol. 40, no. 7, pp. 828-833+840, 2021.

[25] X. S. Han and G. Q. Fan, “The application of three-scale AHP method in mine geological environment assessment_- taking a coal mine in Datong City, Shanxi Province as an example," Groundwater, vol. 35, no. 03, pp. 148-150, 2013.

[26] Z. Li, S. G. Zhou, and K. Wang, "Improvement of analytic hierarchy process (english)," Journal of Zhengzhou University (Science Edition), vol. 1, pp. 41-46, 2008. 